\title{
Goodness beyond Virtue: Jacobins during the french Revolution
}

Jean-Pierre Gross

\section{OpenEdition \\ Journals}

Édition électronique

URL : https://journals.openedition.org/ahrf/981

DOI : $10.4000 /$ ahrf.981

ISSN : $1952-403 X$

Éditeur :

Armand Colin, Société des études robespierristes

Édition imprimée

Date de publication : 1 septembre 2000

Pagination : 151-152

ISBN : 175 pages

ISSN : 0003-4436

Référence électronique

Jean-Pierre Gross, «Goodness beyond Virtue: Jacobins during the french Revolution », Annales historiques de la Révolution française [En ligne], 321 I juillet-septembre 2000, mis en ligne le 21 avril 2004, consulté le 23 avril 2022. URL : http://journals.openedition.org/ahrf/981 ; DOI : https://doi.org/ 10.4000/ahrf.981

Ce document a été généré automatiquement le 23 avril 2022.

Tous droits réservés 


\title{
Goodness beyond Virtue: Jacobins during the french Revolution
}

\author{
Jean-Pierre Gross
}

\section{RÉFÉRENCE}

Patrice Higonnet, Goodness beyond Virtue: Jacobins during the french Revolution, Harvard University Press, Cambridge (Mass.) et Londres, 1998, 397 pages.

1 Depuis le bicentenaire, nombre d'historiens, de part et d'autre de l'Atlantique, remettent en cause une lecture du jacobinisme qui se plaît à y détecter une vision utopique, une fuite en avant ou une dérive totalitariste, au détriment de ses réalisations démocratiques et égalitaires. Si l'orthodoxie révisionniste, dans le sillage de François Furet, s'obstine à considérer jacobinisme et Terreur comme indissociables, ses critiques se sont abstenus jusqu'à présent de contester directement cet amalgame foncièrement pessimiste, se bornant à faire valoir qu'entre les principes jacobins et la fatalité jacobine, il n'existait a priori aucune parenté évidente. Patrice Higonnet, fidèle à la mémoire de son prédécesseur à Harvard, Crane Brinton (dont l'ouvrage sur les jacobins fit du bruit en son temps), s'élève ici contre la condamnation sans appel du jacobinisme. S'il émet un jugement favorable, c'est après s'être livré à une analyse approfondie de la rhétorique et de l'action révolutionnaires, et après avoir affronté sans détour certaines questions fondamentales. Comment se fait-il que, malgré leur refus d'appliquer aveuglément la dictature de salut public, malgré le découplage évident entre la théorie et la pratique, les jacobins de 1793-1794 n'ont pas réussi à éviter la Terreur? Pourquoi leurs convictions démocratiques ont-elles succombé à leurs pulsions sanguinaires? Pourquoi l'instinct fraternel n'a-t-il pas refoulé l'instinct punitif? Pourquoi ce glissement d'apparence inéluctable, cette dégénérescence, du jacobinisme en terrorisme?

2 Certes, la réflexion sur le jacobinisme est de nouveau à l'ordre du jour en France, comme en Amérique, tant chez ses apologistes que chez ses détracteurs. Ainsi Michel 
Vovelle reconnaît que le projet jacobin, même dépouillé de toutes les attentes qu'il ne pouvait remplir, laisse encore de nos jours «le souvenir d'une expérience exaltante» (Les jacobins de Robespierre à Chevènement, éditions de la Découverte, 1999): Patrice Higonnet y voit, à son tour, «un modèle pour la démocratie moderne». À cela, Alain Gérard rétorque que l'héritage jacobin comporte aussi la lourde hypothèque de la terreur régénératrice, destinée à servir de modèle aux totalitarismes du xxe siècle, la création de l'homme nouveau passant par l'extermination de toute une population (Par principe d'humanité: la Terreur et la Vendée, Fayard, 1999).

3 Sensible à cette dialectique, Higonnet traite avec lucidité du dualisme inhérent au jacobinisme, dualisme qu'il n'hésite pas à qualifier de «schizophrénie», et qui a poussé les jacobins à privilégier simultanément la sphère privée et la sphère publique. Il examine de façon exhaustive leurs aspirations confuses: d'une part, leur amour de la liberté et leur défense des libertés individuelles; de l'autre, leur engagement social face aux pressantes sollicitations communautaires. Il démontre, exemples à l'appui, comment, en 1793-1794, le libéralisme individualiste a été éclipsé par l'universalisme autoritaire, l'internationalisme par le nationalisme, le pluralisme par l'intolérance. À ses yeux, l'avènement de la Terreur n'est attribuable ni à l'idéologie, ni aux circonstances, ni à la rigueur logique du discours, mais à l'instabilité qui résulte de l'équilibre précaire entre deux aspirations nobles mais contraires. Contradiction inconciliable qui entraîne le jacobinisme vers la catastrophe. Cependant, la destinée tragique du jacobinisme, voué à l'auto-destruction, ne saurait être assimilée à l'idée d'un totalitarisme systémique. L'idéologie égalitaire, cohérente et volontariste, à penchant dictatorial, n'est pas en elle-même une cause suffisante, il fallait à cette idéologie laïque proche d'une religion le sentiment affectif, a priori vulnérable, prêt à céder aux appréhensions pernicieuses héritées du passé. L'échec ultime du jacobinisme résulterait ainsi, non de la fatalité du mal, mais de la fragilité d'une sensibilité libérale associée à l'inconscient intolérant. C'est l'ascendance absolutiste de l'Ancien Régime qui lui lègue son autoritarisme et son rejet, quasi religieux et moralisateur, de la moindre contestation. La liberté d'opinion et de conscience défendue par la Gironde, et tardivement revendiquée par Camille Desmoulins, ne résiste pas à la nostalgie de l'ordre absolutiste, au besoin d'unicité et d'indivisibilité. Ici, Higonnet se range à l'avis d'Antoine de Baecque en affirmant que si «la Terreur se pose en jugement dernier et réécrit la politique en terme de religion», c'est en raison de l'intolérance inhérente à cette vision absolue des choses, intolérance qui est l'héritage du passé cléricomonarchique.

4 Révision du révisionnisme, donc, mais qui n'en repousse pas toutes les prémisses. S'il admet, après Keith Baker, l'ambiguïté même de l'idée de liberté affirmée en 1789, Higonnet estime que la recherche de la liberté absolue n'était pas condamnée fatalement à engendrer la tyrannie et l'effusion de sang. Il hésite à faire sienne l'approche psycho-sociale (ou freudienne) de Lynn Hunt, qui décèle chez les jacobins un complexe d'Édipe les incitant à tuer leur père-roi-pontife afin de posséder, ou de reposséder, la mère-nation. En revanche, si Higonnet récuse la vision marxiste ou néojacobine de l'histoire révolutionnaire, c'est avec pondération: il y voit l'émergence d'une conscience de classe et reconnaît que là où la confrontation sociale est la plus marquée (à Paris, à Lyon), la lutte à mort qu'elle entraîne ressemble déjà à la lutte des classes. Mais dans son dernier chapitre, Higonnet nous offre une perspective historiographique «en aval», qui nie toute parenté entre jacobinisme et bolchevisme. Refuser de voir un parallélisme entre 1793 et 1917 l'amène à mettre l'accent sur le souci 
de légalité qui caractérise le comportement jacobin. En province, note-t-il, les clubs affichent une fidélité sans faille à la moralité publique et au respect des lois. Même au plus fort de la Terreur, quand la Convention adopte la législation de prairial an II, elle consent à une suspension légale de l'État de droit. Ce souci des formes ne saurait être confondu au bluff mensonger du procès politique totalitaire, destiné à manipuler l'opinion.

Conclusion donc globalement positive, mais qui ne convaincra sans doute pas les sceptiques. Car à force de vouloir concilier les écoles, à force de dépeindre soigneusement toutes les facettes du jacobinisme, pour en récupérer ce qui est récupérable (c'est-à-dire les origines de la démocratie moderne), Higonnet a tendance à brouiller les pistes. Qui sont les jacobins dont il nous conte les gestes? Ces jacobins attirés par la physiocratie, mais qui font appel à la guillotine comme levier économique? Quelle commune mesure y a-t-il entre un Gilbert Romme et un MarcAntoine Baudot? Ne conviendrait-il pas de déterminer avec précision les principaux courants qui composent la famille jacobine, afin d'en mieux cerner les différences et identifier les cas de conscience qui ont failli prévenir le passage de la fraternité à l'intolérance, de la sociabilité à l'exclusion? Espérer tout englober dans un seul vocable, c'est semer le flou. Le «jacobin type» qui en ressort est un personnage bourré de contradictions, et somme toute, antipathique, vaniteux, moralisateur... et violent. Estce là un citoyen modèle digne du nouveau millénaire? 